\title{
The Effective Use of Drama as a Pedagogy for Engaging Students with Disabilities with the Australian Curriculum Learning Areas
}

\author{
${ }^{1}$ Belinda Berrington, ${ }^{2}$ Tracy Cronin, ${ }^{2}$ Jim Green \\ ${ }^{1}$ The Song Room, ${ }^{2}$ Mount Ommaney Special School, Australia
}

\begin{abstract}
Mount Ommaney Special School is located in Brisbane, Queensland, Australia. Mount Ommaney Special School caters for a diverse student population including students with severe and multiple of impairments and complex medical needs. The school campus also includes an Early Childhood Development Program for students from birth to six years old. Mount Ommaney Special School's drama program engages students with disabilities in education through storytelling and dramatic play. This research based pedagogy assists students to engage with the Australian Curriculum in a functional and enjoyable manner, including students who are pre-intentional and early communicative learners. Importantly, it is also being used at Mount Ommaney as a tool to assess student learning against the Australian Curriculum content descriptors. Student engagement is monitored through a unique measuring tool of 'Moments'. Our ongoing data collection shows significant improvements in engagement through participation in the program. In 2011 the program received recognition nationally with a National Australia Bank 'Schools First Impact Award' of \$50,000. This enabled the partnership to commission a professional film maker throughout 2012, and create a whole school digital performance showcasing student achievement and participation, based on the Alison Lester children's book, 'Imagine'. Additionally, an educational documentary 'Just Imagine', which follows the journey of the Mount Ommaney Special School's partnership with The Song Room was launched in May 2013.
\end{abstract}

\section{Introduction}

Mount Ommaney Special School [1] is based in the Brisbane Metropolitan Region in Queensland, Australia. The school was established in 1992 to provide educational programs for students with disabilities, including those who present with high and complex support needs. The 2013 school enrolment figures stand at 57 students from Prep to Grade 12 and 73 children, birth to 6 years, who access the Early Childhood Development Program. Students attend from a wide geographic area covering the south western suburbs of Brisbane. $3 \%$ of students identify as being Aboriginal and $21 \%$ have a language background other than English. Students attend from a wide geographic area covering the south western suburbs of Brisbane and the greater Ipswich region.

Most students are non-verbal with limited ability to communicate in other ways (e.g. signing, body language, eye contact etc.) due to severe physical and intellectual impairments. Our strength has been in implementing individual education programs that address specific needs, enabling students to engage and learn through assistive technology and specialist intervention. Our challenge is to provide all students with opportunities to engage in a range of learning activities that provide access to the curriculum.

Mount Ommaney Special School is divided into the following teaching sectors across the campus: Early Years (birth to pre-prep), Juniors (prep to year 3) Middle (years 4-8), Seniors (years 9-12) and Intensive Interaction (prep to year 12). Each individual sector is aligned with an appropriate curriculum targeted to meet the needs of the students while based on the Australian Curriculum. Classes contain between 4 and 6 students depending on ages and level of complex support needs. Each class is assigned a classroom teacher and teacher aide.

\section{The Song Room}

The Song Room [2] is an Australian national not for profit organisation that provides tailored, longterm music and arts-based programs for children in disadvantaged and high need communities.

The Song Room vision is that all Australian children have the opportunity to participate in music and the arts to enhance their education, personal development and community involvement. The Song Room programs are based on research and have been demonstrated to improve educational and social outcomes and to help schools sustain their own music and arts programs. The Song Room programs include a rigorous evaluation model, but we also believe in the importance of independent research. The Song Room has conducted a major 3 year research project with a number of University and Research partners. Our two most recent research projects were conducted by Educational Transformations and Victoria University. The research report summaries of both of these projects 
can be downloaded from a link on The Song Room website. The Song Rooms delivers its programs to around 250 schools and communities each year and works with over 20,000 children every week.

\subsection{The Partnership}

School based data recorded in Mount Ommaney Special School's end of year student reports semester 2,2009, indicated that students showed increased levels of engagement during the weekly music program in comparison to other learning areas. This was, during 2009, the only arts based specialist subject at Mount Ommaney Special School. The school's Education Program Officer approached The Song Room to investigate implementing a drama program specifically tailored to the school's needs. Following a period of consultation and collaborative planning the partnership was able to identify several key program goals. They are:

- To increase student engagement through drama and creative experiences;

- To increase opportunities for communication, social interaction, creativity and self-expression;

- To develop student's language and human movement skills, and

- To work towards a sustainable program by increasing staff knowledge, skills and confidence in delivering drama programs.

The use of a collaborative process from the inception of the program resulted in a Song Room Teaching Artist being assigned to Mount Ommaney Special School with a 2010 commencement date. Initially the program was to be a 6 month Drama program. As the Teaching Artist had no experience in working with students with a disability, the school supported the Teaching Artist with opportunities to observe the Music Teacher, Speech-Language Pathologist and classroom teachers in order for the Teaching Artist to gain a better understanding of the specific needs and challenges faced by students and staff. Additionally the Teaching Artist was able to familiarise herself with a range of communicative devices and multimodal communication systems.Prior to Teaching Artist commencing the program an extensive questionnaire was distributed to class teachers. The information from the questionnaires was used to inform planning and to ensure that the individual needs and abilities of each diverse class group were addressed.

The 11 classroom Teachers who participated in the initial program were asked to identify their confidence in using drama in the classroom prior to program commencement. $55 \%$ of teachers stated that they were either 'Not Confident' or 'Not At All Confident' in implementing drama in the classroom. (see Graph 1).

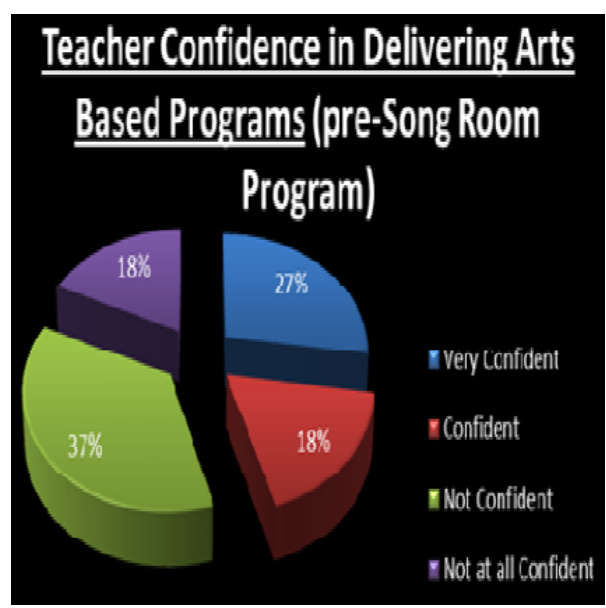

Graph 1. Teacher confidence pre-Song Room Program

This data, along with the observations undertaken by the Teaching Artist and collaborative planning between the Teaching Artist and the individual class teachers informed the design of weekly 30-45 minute drama lessons that provided high quality, studentfocused activities based on each class's current study topic. During 2010 the drama sessions were linked to the Essential Learnings Key Learning Area of The Arts [3].

\section{The Key Elements of the Program}

During the first six months of the program the Teaching Artist took the drama sessions in each class with the support of the classroom teacher and teacher aide. A lesson format was developed for use across the school in order to provide a structure for teachers when planning. The aim of each lesson is to deepen student engagement in a topic by encouraging them to act out a narrative using communication/language skills, movement and social interaction. Lessons also take into consideration each of the students Individual Education Goals, particularly mobility, fine motor and communication goals. Sensory impairments such as visual or hearing impairments are also considered when creating a lesson. Typically, students are initially engaged through a series of warm up activities and then introduced to a storyline. This can be based on a book, a poem, a picture or an idea. Lessons are repeated regularly to enhance learning opportunities for the students. Prior to implementation brainstorming with classroom staff occurred in order to create a shared understanding of expectations for each lesson. Likewise sessions incorporate a cool down technique to signal to students that the session is coming to its conclusion and to aid with student transitioning. 


\subsection{Moments}

As the initial classroom drama sessions were being implemented, the Teaching Artist began to record quantitative data on student engagement, entitled 'Moments'. The data is based on 16 students who participated in the original Teaching Artist workshop program. Following this initial success, the program was then introduced to rest of the school throughout 2010 and to the Early Childhood Development Program in 2012. A 'Moment' is a time of profound understanding or focusing in which a student shows interest or participates or is welcoming of an activity. For each child this takes a different form.

These actions are most profound and are celebrated by teachers as a major step. All 'Moments' noted were observed by the Teaching Artist, class teacher and teacher aides, with the teacher affirming the magnitude of the 'Moment' (see Graph 2).

\subsection{Analysis}

Most students were observed to have one or more 'Moments' with only 6 out of a total 32 not seeming to have experienced any sort of 'Moment' during the drama sessions. This does not mean these 6 students had no positive experiences during the drama sessions and one particularly showed great involvement and focus every session, however they did not exhibit a profound 'Moment'. The data shows the concrete benefits drama has made on students, allowing them to connect and express themselves through play, props, and sensory elements. It is also noted that the evidence of 'Moments' increases as the program progresses, showing that exposure to drama on a weekly basis builds on the students development and allows them to progressively increase their engagement and responsiveness.

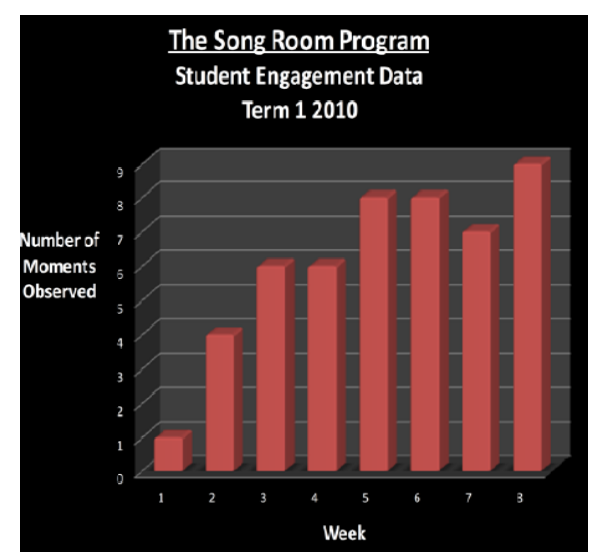

Graph 2. Student engagement data

\subsection{Mentoring}

Following the successful implementation of the drama workshop program and the observed increases in student engagement, Mount Ommaney Special School and The Song Room decided to continue with the program. However, the partnership decided to change the focus of the program, from in class workshops planned and implemented by the Teaching Artist to a program of mentoring. Overall this took 18 months to achieve. During this time the Teaching Artist worked closely with class teachers assisting them with the planning and delivery of their own drama sessions, providing drama expertise and incorporating resources from The Song Room and the school.

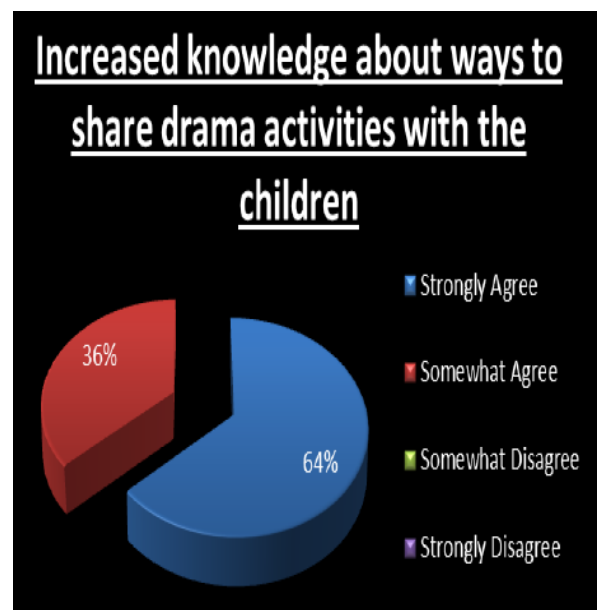

Graph 3. Increased knowledge about ways to share drama activities

This resulted in a significant increase in drama knowledge and a greater understanding of how to impart this knowledge to students within the teaching staff (see Graph 3).

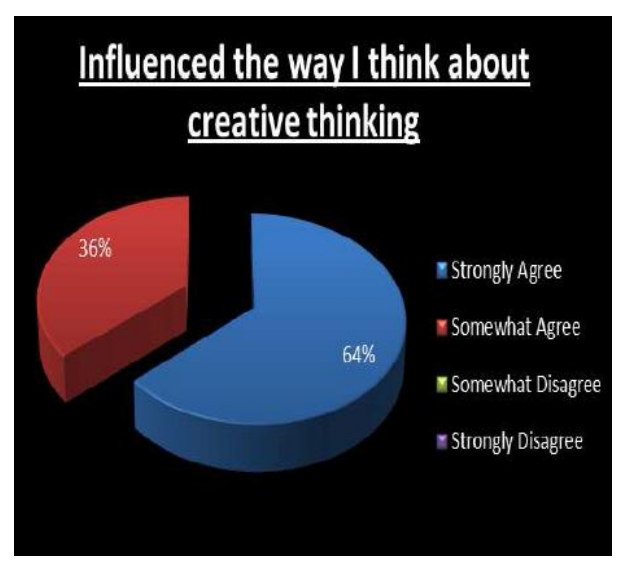

Graph 4. Creative thinking 
Additionally one hundred per cent of classroom teachers reported that this had enhanced their creativity (see Graph 4). Formal and informal approaches were incorporated into the mentoring and professional development program. Formal approaches included targeted professional development in the Arts and drama, while informal school based and classroom based sessions provided the bulk of the mentoring and capacity building program. Over time the Teaching Artist shifted the level of input into the planning and resourcing processes within classrooms and developed a more consultative role within the school. This was supported by Mount Ommaney Special School through targeted non-contact time for teachers that enabled collaborative planning and brain-storming sessions.

The primary aim of the mentoring component continued to have a consistent focus on increasing the classroom teachers' knowledge and skills in creative arts practices. Following this process teachers were again asked to identify their confidence to deliver arts based programs. The results post- mentoring showed that $100 \%$ of teachers rated themselves as either 'Confident' or 'Very Confident' with $82 \%$ in the 'Very Confident' range (see Graph 5). This capacity building model has become the foundation for the sustainability of the program within the school.

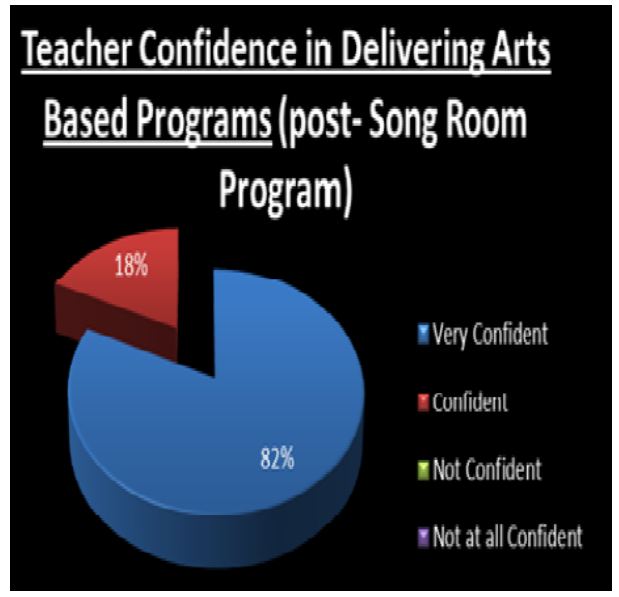

Graph 5. Teacher Confidence post-Song Room program

\section{Pedagogy and Practice}

During the period 2011 - 2012 when Mount Ommaney Special School was implementing the mentoring program within its classrooms across the school and building the capacity of its core teaching staff, systemic changes to curriculum were also being introduced across the influenced by the Melbourne Declaration [4] Mount Ommaney Special school trialled several approaches to curriculum implementation during the 2011 and 2012 period in preparation for the execution of the Australian Curriculum beginning in 2013 under the guidance of the Head of Curriculum. As a result of the trials each schooling sector was assigned age relevant units of work and assessment pieces to guide student learning for the 2013 school year and beyond. The diversity of the student population is also reflected in the range of differentiated curriculum used across the school campus.

The early years (birth to pre-prep) sector of the school uses an integrated approach to unit planning that is based on the Early Years Learning Framework [5], with motivating topics for students. The Junior sector (prep to year 3 equivalent) use differentiated 'curriculum to classroom' units of work for English, Mathematics and Science with the content descriptors used primarily at the Foundation level of the Australian curriculum.

Likewise teachers of the part-time prep students in the Early Childhood Development Program implement differentiated curriculum to classroom units [6] in English, Mathematics and Science based on foundation level content descriptors. The senior sector and the middle sector are both implementing and assessing on the curriculum to classroom curriculum intent [7] units of work in English and Mathematics.

The Intensive Interaction sector of the school use integrated units of work with a focus on Australian Curriculum content descriptors and a focus on communication and the general capabilities. All of these sectors use the drama program as one of the key pedagogies for engaging students with their designated curriculum, particularly in English, as well as for assessment and moderation purposes. One of the senior school assessment tasks focuses on the two following

Australian Curriculum [8] content descriptors in the English learning area.

The first is from the strand Language, sub-strand Language for interaction. Understand that language can be used to explore ways of expressing needs, likes and dislikes.

Elaborations:

1. recognising some of the ways we can use speech, gesture, writing and media to communicate feelings

2. recognising some of the ways emotions and feelings can be conveyed and influenced by visual representations, for example in advertising and animations [9] .

The second content descriptor is from the strand Literature, with the sub-strand - Responding to literature Share feelings and thoughts about the events and characters in texts. 
Elaborations:

1. talking about stories and authors, choosing favourites, discussing how students feel about what happens in stories

2. using art forms and beginning forms of writing to express personal responses to literature and film experiences

3. talking about people, events and ideas in texts, enabling students to connect them to their own experiences and to express their own opinion about what is depicted [10].

\subsection{In the classroom}

In one classroom four of the five students are on a Positive Behaviour Support Plan, none are verbal, two are able to use Boardmaker [11] symbols, and one student is able to use a Pragmatic Organised Dynamic Display [12]. All of the students use gestures to communicate.

The students were introduced to several books that contain emotional elements with one chosen to further explore through drama. Sensory and experiential elements within the text were developed through the drama program in order to enhance the students understanding and identification of emotions. Sessions are regularly filmed using an iPad, for moderation by staff members. Additionally active listening and responding behaviours were regularly assessed using a simple observation sheet. Data from the sheets was used to inform planning. As an additional support the Teaching Artist observed these lessons, providing honest and constructive feedback and an opportunity to reflect on personal practise.

Lesson plans, created around each sectors current area of study, are rotated among the sector teachers. Teacher then adapt the plans to suit the individual students in their classroom. This multileveled approach ensures that the plan addresses the specific needs and abilities of their students.

Lesson plans and associated resources are stored in kits with electronic versions of the lesson plans embedded within units of work across the campus. Data collected through a teacher survey showed an overall enhancement of engagement when involved in the program (see Graph 6) along with a greater ability to concentrate over time (see Graph 7).

Furthermore, during the 2013 school year the implementation of differentiated curriculum to classroom History units across the school is being undertaken by the non-contact time staff using drama as a focus in order to create real life historical experiences for students.

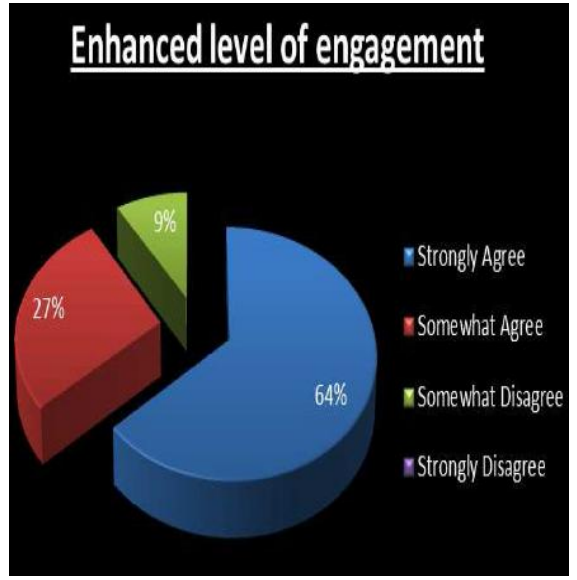

Graph 6. Enhanced level of engagement

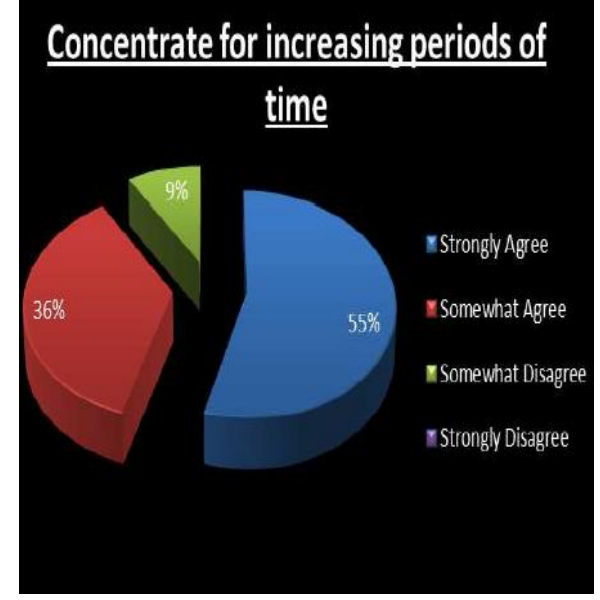

Graph 7. Increased concentration

\section{Family and Community Engagement}

An additional key element of the program was made possible by the partnership between Mount Ommaney Special School and the Song Room obtaining a National Australia Bank Schools Firs Impact Award in 2011. This award supported the creation of a professionally filmed end of year digital performance for families. The performance was based on the book 'Imagine' by Alison Lester [13] with the Author's permission. An approved Australian Curriculum, Curriculum to Classroom resource. Each class or teaching block adapted a section of the book into an age-relevant drama session as a component of their English and literacy learning. The finished performance of 'Imagine' [14] was then screened to families and visitors a school performance evening. Following this it was uploaded to You Tube for extended family and community members to view.

Additionally, during 2012 Soul Vision Films were commissioned to produce a documentary on the program, [14] primarily as an educational tool for other schools. The documentary was launched in 
May 2013 with three separate screenings with the support of Griffith University Film School, including a red carpet night for students and invited guests.

\section{Sustainability}

The sustainability of the drama program was of primary importance to the school. As such the school identified a teacher to work alongside the Teaching Artist with a view to mentoring other teachers across the school with a particular focus on new staff. Historically the management of the program across the school has been overseen by the Principal, the Education Program Officer, the Head of Curriculum, The Song Room Program Coordinator and The Song Room Teaching Artist. During 2013 this team is being extended and joined by the mentor teacher and classroom teachers with a focus on extending the program and the future direction across the campus teachers.

The mentor teacher is also available to give feedback to classroom teachers on their drama pedagogy, with the additional responsibility of maintaining and sourcing resources for the program. Monitoring and review occurs regularly across the campus in a number of ways. The mentor teacher has regular allocated time that is used in a targeted manner to assist classroom. Peer-evaluation and selfreflection through a feedback process occurs in mentoring sessions between teachers and teacher aides. Teachers are allocated non-contact time in teaching sectors to enhance collegial planning.

Additionally six-monthly data and evaluation reviews occur these sessions include the analysis of film footage to gauge subtle responses from students that may otherwise go unnoticed within the classroom.

Likewise regular assessment and moderation periods across the school sectors enable teaching staff to collegially assess the students on their engagement.

\section{Teacher Feedback}

Teacher feedback has been consistently sought throughout the program implementation in the following key areas: Personal Development, Learning Outcomes, Sustainability and Program impacts and Highlights. Teachers were asked to make comments on each of the areas. Comments were consistently positive. Feedback comments around the area of personal Development included "A combination of music and drama as part of our theme work heightens our student's focus and interest. It is a valuable tool to engage them and therefore, to enhance their learning and interactions with others". With another class teacher noting that
"Activities often invite curiosity, leading to increased interaction".

Under Learning Outcomes one class teacher stated that "one student showed a willingness to participate in drama when they had refused to take part in other classroom programmes". Feedback on the sustainability of the program was also positive and noted the pivotal role of the mentoring program. "The mentor's sessions and discussions have given me the knowledge of how to plan a session incorporating music, movement, thematic material and individual and group learning goals".

Comments and feedback on the Program impacts Highlights were generally more student specific with teachers enthusiastic in sharing individual student achievements within the program. With one teacher keenly noting that "a student who seldom tolerates such programs managing to remain in the group for the whole Song Room session, despite regular stressors".

\section{Conclusion}

The effective use of drama as a pedagogy for engaging students with severe and profound impairments with the Australian curriculum has been successful for Mount Ommaney Special School. This has resulted in drama as an essential part of each classroom's daily and weekly programs. The mentoring program has significantly increased the knowledge base of classroom staff across the school at all year levels. The program has significantly enhanced family and community partnerships within the local community.

The embedding of this approach within units of work has given rise to an increase in collegial conversations and a shared language of pedagogy. Considerably apparent during the school assessment and moderation sessions were footage of student engagement is viewed. However, the most important outcome of the program is the engagement of students in a manner that is functional, accessible and fun!

\section{Acknowledgements}

We would like to acknowledge the families, staff and students at Mount Ommaney Special School for their hard work and dedication to this program. The following people for their support: Lynda Fincham, Dr Peter Hegedus from Soul Vision, Anna Carmody from The Song Room and Ric Day our Principal.

\section{References}

[1] Mount Ommaney Special, www.mtommanespecs.eq.edu.au.

[2] The Song Room www.songroom.org.au 
[3] Queensland Government., Queensland Studies Authority 'Essential Learnings. Yrs 1-9, The Arts' www.qsa.qld.edu.au/7262.html

[4] Ministerial Council on Education, Employment, Training and Youth Affairs. 2008. 'The Melbourne Declaration on Educational Goals for Young Australians'.

[5] COAG (Council of Australian Governments), 2009, 'Being, Belonging, Becoming'. The Department of Education, Employment and Workplace, The Commonwealth of Australia.

[6] Qld. Govt. Curriculum into the classroom. http://education.qld.gov.au/c2c/index.html

[7] Curriculum into the classroom for students with a disability, http://education.qld.gov.au/studentservices/ learning/disability-partnership/disability-curriculumtoclassroom.html.

[8] ACARA Australian Curriculum Assessment and Reporting Authority, www.australiancurriculum.edu.au/ English/Curriculum/F-10.

[9] ACARA Australian Curriculum Assessment and Reporting Authority, www.australiancurriculum.edu.au/ English/Curriculum/F-10.

[10] ACARA Australian Curriculum Assessment and Reporting Authority, www.australiancurriculum.edu.au/ English/Curriculum/F-10.

[11] www.Mayer-Johnson.com/what-isboardmaker/

[12] Porter, Gayle. PODD. Pragmatic Organisation Dynamic Display Communication Books, www.lburkhart.com/PODDinfo.html

[13] Lester, Alison. 'Imagine'. Allen and Unwin.

[14] 'Imagine' school performance.

http://www.youtube.com/watch?v=eTx8_RwrUu8

[15] 'Just Imagine' documentary trailer. http://www.youtube.com/watch?v=UYxW_x1wlyo. 